\title{
CONTENT BASED DAN COLLABORATIVE FILTERING PADA REKOMENDASI TUJUAN PARIWISATA DI DAERAH YOGYAKARTA
}

\author{
Aprilia Saptu Ningrum ${ }^{(1)}$, Heru Cahya Rustamaji(2), Yuli Fauziah ${ }^{(3)}$ \\ Jurusan Teknik Informatika Fakultas Teknik Industri UPN “Veteran” Yogyakarta \\ Jl. Babarsari 2 Tambakbayan Yogyakarta

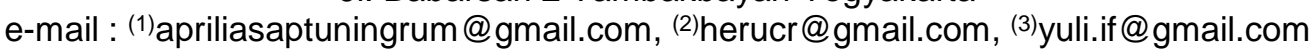

\begin{abstract}
One of the famous cities for tourism is Yogyakarta. Yogyakarta has a variety of tourist destinations, staring from nature tourism, cultural and historical tourism, museums tour, beach tourism and special interest tours. both from domestic and foreign tourists. many tourist destinations in Yogyakarta, often makes tourists confused in choosing their destination. Based on these problem, then a system of recommendations is created that it can help tourists choose their destination. In research a system of recommendations for tourism destinations has been built in the Yogyakarta. This study uses a hybrid filtering method that is a combination of two methods, collaborative filtering methods and content-based filtering. This system also provides detailed tourist information starting from the description of the tourist attractions, operating hours and the price of admission, directions to the tourist attractions, and tourists can provide comments and ratings. The results of this study use black-box testing, indicating that this application can work correctly. Testing with alpha test with 10 respondents resulted in $52.6 \%$ giving a Good answer and with a beta test with 40 respondents resulted in $77.3 \%$ giving agree answer. This indicates that the system functions that have been built can meet the needs of users.
\end{abstract}

Keywords : system recommendation, hybrid filtering, content-based filtering, collaborative filtering, tour destination in yogyakarta

\section{Abstrak}

Salah satu kota yang terkenal akan tempat wisatanya adalah Yogyakarta. Yogyakarta memiliki beragam destinasi wisata, mulai dari wisata alam, wisata budaya dan sejarah, wisata museum, wisata pantai dan wisata minat khusus. Setiap tahunnya wisatawan yang datang ke Yogyakarta mengalami peningkatan, baik dari wisatawan domestik maupun wisatawan mancanegara. Banyaknya destinasi wisata yang ada di Yogyakarta, sering membuat wisatawan bingung dalam memilih tujuan wisatanya. Berdasarkan masalah tersebut maka di buatlah sebuah sistem rekomendasi agar dapat membantu wisatawan dalam memilih tujuan wisatanya. Pada penelitian ini telah dibangun sebuah sistem rekomendasi tujuan pariwisata di daerah Yogyakarta. Penelitian ini menggunakan metode hybrid filtering yaitu gabungan dua metode, metode collaborative filtering dan content-based filtering. Sistem ini juga memberikan informasi tempat wisata yang detail mulai dari penjelasan tempat wisata tersebut, jam operasional dan harga tiket masuk, serta ada petunjuk arah ke tempat wisata tersebut, dan wisatawan bisa memberikan komentar serta rating. Hasil dari penelitian ini menggunakan pengujian black-box, menunjukkan bahwa aplikasi ini dapat bekerja dengan benar. Pengujian dengan alpha test dengan 10 responden menghasilkan 52.6\% memberikan jawaban Baik serta dengan beta test dengan 40 responden menghasilkan $77.3 \%$ memberikan jawaban SETUJU. Hal ini menunjukkan bahwa fungsi sistem yang telah dibangun dapat memenuhi kebutuhan dari pengguna.

Kata Kunci : sistem rekomendasi, hybrid filtering, content-based filtering, collaborative filtering, tujuan wisata di Yogyakarta

\section{PENDAHULUAN}

Pariwisata adalah salah satu sektor penting bagi perekonomian Indonesia. Keindahan alam dan keanekaragaman budaya merupakan nilai lebih yang dianggap dapat menarik para wisatawan (Wipraja, Darwiyanto, \& Bijaksana, 2017). Salah satu kota yang terkenal di Indonesia akan 
tempat wisatanya adalah Yogyakarta. Menurut data statistik kepariwisataan DIY tahun 2017 sebanyak 25.950.793 wisatawan datang ke Yogyakarta. Berbagai jenis objek wisata mulai dari wisata alam hingga wisata keagamaan ada di Yogyakarta, sehingga banyak dikunjungi wisatawan domestik maupun wisatawan mancanegara (Wipraja, Darwiyanto, \& Bijaksana, 2017).

Ketika akan berwisata tentu berbagai hal akan menjadi pertimbangan bagi wisatawan, salah satunya adalah membuat rencana perjalanan (Wipraja, Darwiyanto, \& Bijaksana, 2017). Biasanya wisatawan menggunakan jasa agen wisata atau pramuwisata, namun ada juga wisatawan yang merencanakan sendiri tujuan wisatanya, sehingga memerlukan waktu yang lebih banyak untuk mengumpulkan informasi. Informasi yang begitu banyak kadang sering membuat wisatawan bingung dalam memilih tujuan wisatanya.

Berdasarkan masalah tersebut maka dibutuhkan sebuah sistem yang mampu memberikan rekomendasi tempat wisata. Sistem rekomendasi digunakan karena mampu memberikan penyaringan dari informasi yang sangat banyak (overload) di dunia maya untuk memberikan saran/rekomendasi pilihan objek wisata. Perkembangan jumlah informasi yang banyak di dunia maya menyebabkan sulitnya menemukan informasi yang tepat dan sesuai dengan selera/preferensi yang diinginkan wisatawan (Arief, 2016).

Penelitian ini menggunakan pendekatan hybrid filtering agar dapat mengatasi hal tersebut, hybrid filtering gabungan dua metode, yaitu metode collaborative filtering dan content-based filtering. Sistem rekomendasi berbasis konten (Content-based Recommendation System) menggunakan ketersediaan konten (sering juga disebut dengan fitur, atribut atau karakteristik) sebuah item sebagai basis dalam pemberian rekomendasi (Ricci et al, 2011). Ide utama dalam sistem rekomendasi collaborative filtering adalah untuk memanfaatkan opini pengguna lain yang ada untuk memprediksi item yang mungkin akan disukai/diminati oleh seorang pengguna (Ricci et al, 2011).

\section{METODOLOGI PENELITIAN}

Metode pengembangan sistem yang digunakan dalam penelitian ini menggunakan metode grapple. Tahapan metode grapple meliputi pengumpulan kebutuhan (requirement gathering), analisis (analysis), desain (design), pengembangan (development), dan penyebaran (deployment). Namun dalam penelitian ini hanya sampai pada tahap pengembangan (development).

\subsection{Pengumpulan Kebutuhan (Requirement Gathering)}

Pengumpulan kebutuhan (requirement gathering) terdiri dari perangkat keras yang digunakan, perangkat lunak yang digunakan untuk membangun aplikasi dan arsitektur sistem.

\subsubsection{Perangkat Keras Yang Digunakan Untuk Membangun Aplikasi}

Beberapa perangkat keras (hardware) yang digunakan saat pembuatan aplikasi dapat dilihat pada tabel berikut.

Tabel 1. Tabel kebutuhan perangkat keras (hardware)

\begin{tabular}{|c|l|l|}
\hline No. & \multicolumn{1}{|c|}{ Perangkat Keras } & \multicolumn{1}{c|}{ Keterangan } \\
\hline \multirow{4}{*}{1.} & Notebook & HP Pavilion g4 \\
\cline { 2 - 3 } & Proccesor & Intel(R) Core(TM) i7-3612QM CPU @2.10GHz \\
\cline { 2 - 3 } & Random Acces Memory (RAM) & $4 \mathrm{~GB}$ \\
\cline { 2 - 3 } & Hardisk & $750 \mathrm{~GB}$ \\
\cline { 2 - 3 } & Layar display & 14 " diagonal HD BrightView LED-backlit (1366 x 768) \\
\hline \multirow{3}{*}{2.} & Handphone & Oppo F3 \\
\cline { 2 - 3 } & Prosessor & $1.5 \mathrm{GHz}$ octa-core MediaTek MT6750 \\
\cline { 2 - 3 } & RAM & $4 \mathrm{~GB}$ \\
\hline
\end{tabular}




\begin{tabular}{|c|l|l|}
\hline No. & \multicolumn{1}{|c|}{ Perangkat Keras } & \multicolumn{1}{c|}{ Keterangan } \\
\hline & Memori Internal & $32 \mathrm{~GB}$ \\
\cline { 2 - 3 } & Memori External & $128 \mathrm{~GB}$ \\
\hline
\end{tabular}

\subsubsection{Perangkat Lunak Yang Digunakan Untuk Membangun Aplikasi}

Beberapa perangkat lunak (software) yang digunakan didalam pembuatan aplikasi ini dapat dilihat pada tabel berikut ini.

Tabel 2. Tabel kebutuhan perangkat lunak (software)

\begin{tabular}{|c|l|l|}
\hline No & \multicolumn{1}{|c|}{ Perangkat Lunak } & \multicolumn{1}{c|}{ Keterangan } \\
\hline 1 & Wndows 7 & Sistem operasi \\
\hline 2 & Marshmallow 6.0 & Sistem operasi Smartphone \\
\hline 3 & Android Studio & Perangkat lunak untuk desain interface dan code editor \\
\hline 4 & Android SDK & Perangkat lunak untuk proses debugging dari code editor \\
\hline 5 & Php My Admin & Perangkat lunak untuk database system \\
\hline 6 & Star UML & Perangkat lunak untuk desain pemodelan UML \\
\hline 7 & Google Chrome & Perangkat lunak untuk mejalankan web service dan hosting \\
\hline 8 & Balsamiq Mockups 3 & Perangkat lunak Pembuatan desain user interface aplikasi \\
\hline
\end{tabular}

\subsubsection{Arsitektur Sistem}

Arsitektur sistem yang digunakan dalam aplikasi ini dapat dilihat pada gambar dibawah ini.

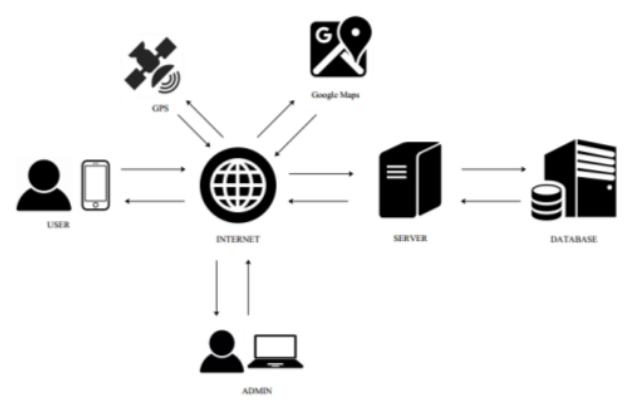

Gambar 1. Arsitektur Sistem

\subsection{Analisis (Analysis)}

Analisis merupakan tahap pertama dari pengembangan sistem, dalam penelitian ini menggunakan metode grapple. Penelitian ini membahas tentang analisis perancangan sistem yang akan dibangun menggunakan UML sebagai bahasa spesifikasi standar untuk mendokumentasi, menspesifikasi, dan membangun sebuah sistem dengan menggunakan beberapa diagram.

\subsubsection{Identifikasi Kebutuhan Sistem}

Aksi identifikasi kebutuhan sistem ini menghasilkan produk diagram use case. Dalam aplikasi ini dapat diidentifikasi dua diagram use case yaitu diagram use case client dan diagram use case server.

\subsubsection{Diagram Use Case Client}

Diagram use case client terdapat satu aktor yaitu user. User dapat menjalankan delapan use case secara umum, yaitu di antaranya dapat melihat lokasi wisata yang ada di Yogyakarta dari map, dan user dapat melihat posisinya dari map. User dapat melakukan tindakan use case yang lainnya yaitu dapat melihat kategori wisata dan rekomendasi wisata, melihat list wisata, melihat deskripsi wisata, memberikan review, memberi favorit wisata dan melihat lokasi wisata. 


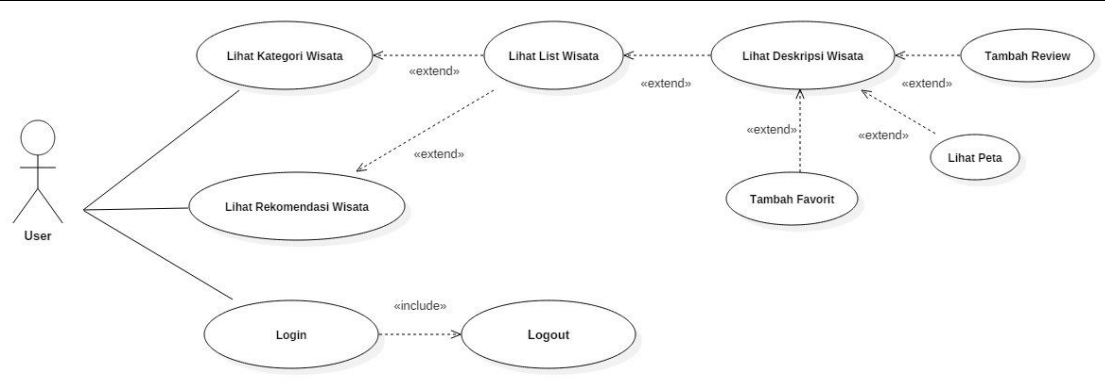

Gambar 2. Diagram Use Case Client

\section{HASIL DAN PEMBAHASAN}

Hasil dari penelitian ini adalah membuat aplikasi rekomendasi tujuan pariwisata di daerah Yogyakarta. Metode yang digunakan adalah metode hybrid (content based dan colllaborative filtering). Rekomendasi digunakan dengan perhitungan hybrid filtering melalui pendekatan linear combination.

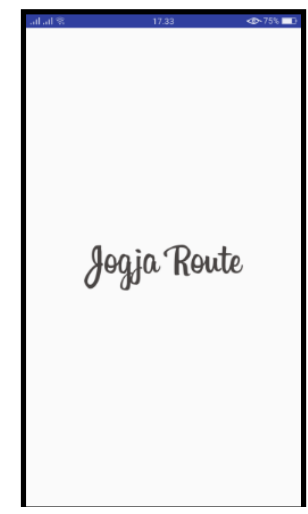

Gambar 5. Tampilan awal aplikasi

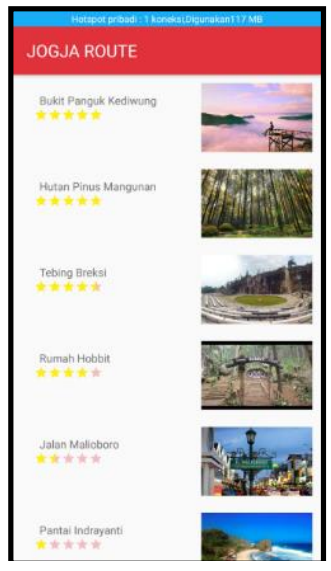

Gambar 6. Tampilan rekomendasi

\subsection{Perancangan Model untuk Perhitungan}

Data yang dibutuhkan untuk pemberian rekomendasi pariwisata berdasarkan fasilitas yang akan berwisata, harga tiket masuk, dan kategori wisata. Berikut data yang digunakan dalam perhitungan hybrid filtering. 
Tabel 3. Data yang digunakan untuk Perhitungan

\begin{tabular}{|c|l|l|}
\hline No & \multicolumn{1}{|c|}{ Kriteria } & \multicolumn{1}{c|}{ Subkriteria } \\
\hline 1. & Fasilitas & 1. Banyak ( lebih dari 4) \\
& & 2. Sedikit (kurang dari 4) \\
\hline 2. & Harga & 1. Murah (1.000 - 50.000) \\
& & 2. Sedang $(51.000-100.000)$ \\
\hline 3. & Kategori Wisata & 3. Mahal (diatas 100.000) \\
& & 1. Wisata Alam \\
& & 2. Wisata Budaya \& Sejarah \\
& & 3. Wisata Pantai \\
& & 4. Wisata Museum \\
\end{tabular}

\subsection{Pembahasan Metode}

Pembahasaan ini akan menjelaskan rekomendasi yang dihasilkan oleh program dengan metode hybrid. Penulis akan membuat sebuah skenario penggunaan sistem rekomendasi. Berikut merupakan rincian skenario pengujian data pada sistem rekomendasi tujuan pariwisata di daerah Yogyakarta.

Tabel 4. Beberapa tempat wisata.

\begin{tabular}{|c|c|l|c|}
\hline ID & Nama Tempat Wisata & \multicolumn{1}{|c|}{ Fitur Yang Dimiliki } & Rating \\
\hline 11 & Pantai Parangtritis & $\begin{array}{l}\text { Banyak Fasilitas, Wisata Pantai dan Harga Tiket } \\
\text { Murah }\end{array}$ & 4 \\
\hline 36 & Candi Prambanan & $\begin{array}{l}\text { Banyak Fasilitas, Wisata Budaya \& Sejarah dan } \\
\text { Harga Tiket Murah }\end{array}$ & 5 \\
\hline 37 & Candi Ratu Boko & $\begin{array}{l}\text { Banyak Fasilitas, Wisata Budaya \& Sejarah dan } \\
\text { Harga Tiket Murah }\end{array}$ & 3 \\
\hline 47 & $\begin{array}{l}\text { Jogja Bay Pirates Adventure } \\
\text { Waterpark }\end{array}$ & $\begin{array}{l}\text { Banyak Fasilitas, Wisata Minat Khusus dan } \\
\text { Harga Tiket Sedang }\end{array}$ & 4 \\
\hline 42 & Museum Affandi & $\begin{array}{l}\text { Sedikit Fasilitas, Wisata Museum dan Harga } \\
\text { Tiket Murah }\end{array}$ & $?$ \\
\hline
\end{tabular}

3.2.1. Perhitungan Content Based

Pertama-tama, hitung prediksi rating dengan menggunakan metode content based. Tabel item feature-nya sebagai berikut ini.

Tabel 5. Item feature $\mathrm{u}_{45}$

\begin{tabular}{|c|c|c|c|c|c|c|c|c|c|c|c|}
\hline & $\mathbf{F}_{\mathbf{1}}$ & $\mathbf{F}_{\mathbf{2}}$ & $\mathbf{F}_{\mathbf{3}}$ & $\mathbf{F}_{\mathbf{4}}$ & $\mathbf{F}_{\mathbf{5}}$ & $\mathbf{F}_{\mathbf{6}}$ & $\mathbf{F}_{\mathbf{7}}$ & $\mathbf{F}_{\mathbf{8}}$ & $\mathbf{F}_{\mathbf{9}}$ & $\mathbf{F}_{\mathbf{1 0}}$ & Rating \\
\hline $\mathrm{i}_{11}$ & 1 & 0 & 0 & 0 & 1 & 0 & 0 & 1 & 0 & 0 & 4 \\
\hline $\mathrm{i}_{36}$ & 1 & 0 & 0 & 1 & 0 & 0 & 0 & 1 & 0 & 0 & 5 \\
\hline $\mathrm{i}_{37}$ & 1 & 0 & 0 & 1 & 0 & 0 & 0 & 1 & 0 & 0 & 3 \\
\hline $\mathrm{i}_{47}$ & 1 & 0 & 0 & 0 & 0 & 0 & 1 & 0 & 1 & 0 & 4 \\
\hline
\end{tabular}

Tabel 5. adalah tabel item feature yang dimiliki seorang pengguna $\mathrm{u}_{45}$. Selanjutnya, hitung bobot pengguna terhadap masing-masing fitur dengan menggunakan rumus.

$$
w\left(u, j_{k}\right)=\frac{1}{\left|I_{u}\right|} \sum_{i \in I_{u}} x(i, j) r(u, i)
$$

Keterangan :

a. $w\left(u, j_{k}\right)$ merupakan bobot yang dimiliki oleh pengguna $u$ terhadap fitur $j_{k}$.

b. $I_{u}$ merupakan satu set item yang telah di rating oleh pengguna $u$. 
c. $x(i, j)$ merupakan nilai kehadiran (angka 1 atau 0 ) sebuah fitur di dalam sebuah item.

d. $r(u, i)$ merupakan rating yang diberikan pengguna $u$ terhadap item $i$.

Untuk lebih lengkapnya, bobot pengguna terhadap masing-masing fitur dapat dilihat pada tabel 6.

Tabel 6. Hasil perhitungan bobot

\begin{tabular}{|c|c|c|c|c|c|c|c|c|c|c|}
\hline & $\mathrm{F}_{1}$ & $\mathrm{~F}_{2}$ & $\mathrm{~F}_{3}$ & $\mathrm{~F}_{4}$ & $\mathrm{~F}_{5}$ & $\mathrm{~F}_{6}$ & $\mathrm{~F}_{7}$ & $\mathrm{~F}_{8}$ & $\mathrm{~F}_{9}$ & $\mathrm{~F}_{10}$ \\
\hline user & 4 & 0 & 0 & 2 & 1 & 0 & 1 & 3 & 1 & 0 \\
\hline
\end{tabular}

Kemudian, prediksi rating tempat wisata dengan menggunakan rumus.

$$
R^{\prime}(u, i)=\frac{1}{\left|D_{i}\right|} \sum_{j \in D_{i}} w(u, j)
$$

Keterangan :

a. $\quad R^{\prime}(u, i)$ merupakan prediksi rating pengguna $u$ terhadap item $i$.

b. $D_{i}$ merupakan fitur yang muncul di dalam item $i$.

\subsubsection{Perhitungan Collaboratif Filtering}

Setelah didapatkan hasil perhitungan prediksi rating secara content based, selanjutnya menghitung prediksi rating secara collaborative filtering. Tabel 7 merupakan matrix rating antara pengguna utama $\left(\mathrm{u}_{45}\right)$ dengan pengguna lain yang mirip (neighbor).

Tabel 7. Matrix rating user $x$ item

\begin{tabular}{|c|c|c|c|c|c|}
\hline ID & $\mathbf{i}_{11}$ & $\mathbf{i}_{36}$ & $\mathbf{i}_{37}$ & $\mathbf{i}_{47}$ & $\mathbf{i}_{42}$ \\
\hline $\mathrm{U}_{45}$ & 4 & 5 & 3 & 4 & $?$ \\
\hline $\mathrm{U}_{46}$ & 5 & 4 & 4 & 3 & 4 \\
\hline $\mathrm{U}_{43}$ & 3 & 5 & 4 & 5 & 3 \\
\hline $\mathrm{U}_{47}$ & 5 & 3 & 4 & 3 & 5 \\
\hline $\mathrm{U}_{48}$ & 4 & 3 & 5 & 3 & 4 \\
\hline
\end{tabular}

Kemudian, hitung kemiripan antara $\mathrm{u}_{45}$ dengan semua pengguna neighbor tersebut dengan menggunakan rumus cosine based similiarity.

$$
\operatorname{sim}\left(u, u^{\prime}\right)=\frac{\left(\sum_{i \in I\left(u, u^{\prime}\right)^{R}}(u, i) R\left(u^{\prime}, i\right)\right)}{\left(\sqrt{\sum_{i \in I\left(u, u^{\prime}\right)^{R}(u, i)^{2}}} \sqrt{\sum_{\left.\left.i \in I\left(u, u^{\prime}\right)^{R(u, i},\right)^{2}\right)}}\right.}
$$

Keterangan :

a. $\operatorname{sim}\left(u, u^{\prime}\right)$ adalah kemiripan antara pengguna $u$ dengan $u^{\prime}$.

b. $I\left(u, u^{\prime}\right)$ adalah satu set item yang telah di rating oleh kedua pengguna $u$ dengan $u^{\prime}$.

Kemudian, hitung prediksi rating tempat wisata tersebut menggunakan rumus weighted sum.

$$
R^{\prime}(u, i)=\frac{1}{\sum u^{\prime} \in N(u)\left|\operatorname{sim}\left(u, u^{\prime}\right)\right|} \sum_{u^{\prime} \in N(u)} \operatorname{sim}\left(u, u^{\prime}\right) * R\left(u^{\prime}, i\right)
$$

Keterangan :

a. $\quad R^{\prime}(u, i)$ adalah prediksi rating pengguna $u$ terhadap item $i$.

b. $R\left(u^{\prime}, i\right)$ adalah rating pengguna $u^{\prime}$ (pengguna selain $u$ ) terhadap item $i$.

c. $\operatorname{sim}\left(u, u^{\prime}\right)$ adalah kemiripan antara pengguna $u$ dengan $u^{\prime}$.

d. $N(u)$ adalah satu set pengguna lain yang mirip dengan pengguna $u$.

\subsubsection{Perhitungan Hybrid Filtering}

Berikut ini merupakan hasil perhitungan yang dilakukan oleh dua buah metode content based dan collaborative filtering. 
- Content Based

$$
\mathrm{R}_{\mathrm{cb}}^{\prime}=1,2
$$

- Collaborative Filtering

$$
R_{\text {cf }}^{\prime}=3,990787902
$$

Hasil perhitungan secara hybrid (linear combination) yang dihitung dengan menggunakan rumus (menggunakan bobot yang sama di kedua metode tersebut).

$$
R_{\text {hybrid }}=\left(w_{1} R_{1}+w_{2} R_{2}+\ldots w_{n} R_{n}\right) /\left(w_{1}+w_{2}+\ldots w_{n}\right)
$$

Keterangan :

a. $R_{\text {hybrid }}$ merupakan prediksi rating hybrid.

b. $w_{n}$ merupakan bobot prediksi rating dengan teknik/metode ke- $n$.

c. $R_{n}$ merupakan prediksi rating dengan teknik/metode ke- $n$.

\subsection{Pengujian Sistem}

\section{a. Pengujian Alpha}

Pengujian alpha dilakukan pada sisi pengembang (developer). Perangkat lunak digunakan di dalam setting yang natural dengan pengembang yang melihat dari sisi pengguna dan merekam semua kesalahan dan masalah penggunaan. Para penguji alpha test adalah Mahasiswa dan Mahasiswi. Berdasarkan penilaian terhadap sistem, hasil uji validasi untuk alpha test menghasilkan $52.6 \%$ responden memberikan jawaban Baik maka dapat disimpulkan bahwa fungsi aplikasi yang telah dibangun telah memenuhi kebutuhan dari pengguna akhir.

\section{b. Pengujian Beta}

Pengujian beta test adalah masyarakat umum yang mengambil contoh beberapa mahasiswa/mahasiswi, freelancer, ibu rumah tangga, pegawai, pedagang, psikolog, PNS, yang ada dan telah bersedia secara sukarela membantu proses pengujian. Berdasarkan penilaian terhadap sistem, hasil uji validasi untuk beta test menghasilkan $77.3 \%$ responden memberikan jawaban Setuju maka dapat disimpulkan bahwa fungsi aplikasi yang telah dibangun telah memenuhi kebutuhan dari pengguna akhir.

\section{KESIMPULAN}

Setelah melewati tahap pengimplementasian dan pengujian terhadap sistem, maka terdapat beberapa kesimpulan yang ditemukan pada penelitian ini, yaitu :

1. Penelitian ini memberikan rekomendasi tempat wisata berdasarkan hasil prediksi nilai rating baru menggunakan metode hybrid (content based dan collaborative filtering).

2. Penelitian ini membantu wisatawan dalam memilih tujuan wisata di daerah Yogyakarta.

3. Hasil pengujian menggunakan metode black-box menunjukkan bahwa semua fungsi dapat bekerja dengan benar. Adapun hasil dari pengujian black-box dengan alpha test pada 10 responden ini menghasilkan $52.6 \%$ memberikan jawaban Baik, serta dengan beta test pada 40 responden ini menghasilkan $77.3 \%$ memberikan jawaban Setuju.

Penulis ingin memberikan beberapa saran untuk penelitian di bidang sistem rekomendasi selanjutnya, yaitu :

1. Penelitian ini menggunakan metode hybrid (content based dan collaborative filtering), oleh karena itu dikembangkan dan diteliti lebih lanjut dengan metode hybrid (content based dan collaborative filtering) dengan multi criteria rating.

2. Penelitian selanjutnya disarankan untuk tidak hanya menggunakan alat berupa rating sebagai pembentuk user profile, namun menggunakan banyak masukan seperti komentar, like/dislike, atau yang lainnya. 


\section{DAFTAR PUSTAKA}

Afifi, W., 2015. Implementasi Hybrid (Content Based Dan Collaborative Filtering) Pada Sistem Rekomendasi Software Antivirus Dengan Multi-Criteria Rating.

Arief, A., 2016. Rancang Bangun Sistem Rekomendasi Pariwisata Mobile Advertising Menggunakan Metode Hybrid Filtering Sebagai Pemberdayaan Masyarakat Usaha Kecil Menengah (Ukm) Di Pulau Ternate. Protek 3, 20-25.

Arief, A., Widyawan, W., Hantono, B.S., 2012. Rancang Bangun Sistem Rekomendasi Pariwisata Mobile Dengan Menggunakan Metode Collaborative Filtering Dan Location Based Filtering. J. Nas. Tek. Elektro Dan Teknol. Inf. Jnteti 1. Https://Doi.Org/10.22146/Jnteti.V1i3.129

Dewi, E.K., 2013. Pengembangan Aplikasi Sistem Pendukung Keputusan Untuk Menentukan Tujuan Wisata Di Yogyakarta Berbasis Mobile Website (S2). Uajy.

Dzumiroh, L., Saptono, R., 2016. Penerapan Metode Collaborative Filtering Menggunakan Rating Implisit Pada Sistem Perekomendasi Pemilihan Film Di Rental Vcd. Itsmart J. Teknol. Dan Inf. 1, 54-59. Https://Doi.Org/10.20961//ts.V1i2.590

Ririn, I., 2015. Sistem Rekomendasi Pada E-Market Produk Umkm Dinpora Propinsi Jawa Tengah Dengan Menggunakan Content Based Filtering. Skripsifakultas IImu Komput.

Wahyo, B.T., Anggriawan, A., 2015. Sistem Rekomendasi Paket Wisata Se-Malang Raya Menggunakan Metode Hybrid Content Based And Collaborative. J. IIm. Teknol. Inf. Asia 9, 6-13.

Wahyudi, R., Utami, E., Arief, M.R., 2016. Sistem Pakar E-Tourism Pada Dinas Pariwisata D.I.Y Menggunakan Metode Forward Chaining. Data Manaj. Dan Teknol. Inf. Dasi 17, 67-75. 